Research Article

\title{
Experimental Study of the Effect of Confining on the Development of Fire in a Closed Compartment
}

\author{
Fidel Meskeoule Vondou, ${ }^{1,2}$ Claude Valery Ngayihi Abbe $\mathbb{D}^{1,2}{ }^{1,2}$ Justin Tégawendé Zaida, ${ }^{3}$ \\ Philippe Onguene Mvogo, ${ }^{4}$ and Ruben Mouangue $\mathbb{D}^{1,4}$ \\ ${ }^{1}$ National Higher Polytechnic School, University of Douala, Douala, Cameroon \\ ${ }^{2}$ Laboratory of Energy, Materials, Modelling and Methods, University of Douala, Douala, Cameroon \\ ${ }^{3}$ Department of Physics, University of Fada, Fada-Ngourma, Gourma Province, Burkina Faso \\ ${ }^{4}$ Group of Research in Combustion and Green Technology, University of Ngaoundere, Ngaoundere, Cameroon
}

Correspondence should be addressed to Ruben Mouangue; r_mouangue@yahoo.fr

Received 15 November 2020; Revised 19 January 2021; Accepted 5 February 2021; Published 12 February 2021

Academic Editor: Benjamin Shaw

Copyright (C) 2021 Fidel Meskeoule Vondou et al. This is an open access article distributed under the Creative Commons Attribution License, which permits unrestricted use, distribution, and reproduction in any medium, provided the original work is properly cited.

\begin{abstract}
Backdraft is a complex phenomenon which occurs during cases of confined fires. It appears by a fast deflagration which occurs after the introduction of oxygen into a compartment filled with hot gases rich in unburned combustible vapor. Practically, this situation could occur at the time of intervention of firemen who break the door or when a window breaks under the action of thermal stresses. Based on a strong experimental campaign, the present paper aimed to make a quantitative investigation of the effect of confining on a totally closed fire. With this focus, fire tests were carried out in a completely closed room of dimensions $1.20 \mathrm{~m} \times 1.20 \mathrm{~m} \times 1.02 \mathrm{~m}$, with five sources of fire of different heat release rates. The same fire sources were also tested in a free atmosphere in order to get reference data. After a statistical study of data, a comparative analysis between both results has been done. Its outcome is that confining has a major impact on the quality of combustion and on the fire duration. More precisely, it has been noticed comparatively to fire tests in free atmosphere that confining increases the fire duration by 14.85 percent while it decreases the heat release rate by 21.72 percent.
\end{abstract}

\section{Introduction}

The majority of fires in which firemen are confronted occur in buildings, or, in a more general way, in closed or lightly opened volumes. The occurrence of some accidents during recognition and operation of extinction of these fire incidents makes essential the adaptation of the knowledge and techniques of intervention. Thus, these fires, sometimes initially of weak width, can develop very quickly producing a great quantity of smoke and causing, under the effect of heat, the distillation of fuel gases through pyrolysis of materials contained in the volume. At this stage, the conditions of ventilation are decisive for the evolution of the fire towards dangerous and very dreaded phenomena of the firemen [1-5]. These phenomena can be a backdraft which is the spontaneous explosion of unburned gases accumulated in the volume of fire; that is to say, flashover which is the generalized ignition of all combustible materials present in a partially opened volume. Indeed according to the literature, fires in the interior medium were the subject of several studies on a double experimental and numerical level [6-22].

Starting from the initialization phase to the extinction phase, works of authors on confined fires show that several parameters significantly influence its behavior which can lead to the occurring of the phenomenon of backdraft. Fleischmann et al. [23] showed that the volume of unburned gases must be at least equal to $15 \%$ of the volume of the compartment so that backdraft can occur. Gottuk et al. [24] showed in their work that the atmosphere of a compartment with fire becomes vitiated and ready to explode when the critical mass fraction of combustible's vapor of 0.16 is reached. By using methane as the fuel source of fire in the 
experimental domain, Weng and Fan [25] found a critical mass fraction of unburned gases of $9.8 \%$. Guigay et al. [26] carried out an experiment on the possible actions being able to prevent the occurring of backdraft that showed that the cooling of gases in the enclosure on fire would reduce the difference in density between hot gases and cooled gases. This would therefore decrease the effects of the relaxation of hot gases in the event of an abrupt contribution of fresh air. Pérez et al. [27] evaluated the effect of the obstacles to the entering draught on prerequisites of Backdraft. It shows that the presence of the obstacles in a compartment with fire affects the velocity of the gravity current and the level of mixing between fresh gases and vitiated gases. Wu et al. [28] studied the effects of the variation of dimensions of the opening on hot gases in a compartment and they concluded that ventilation is a key parameter determining the occurrence of this phenomenon. More recently, Vondou et al. [29] showed that the disposition of openings has an influence on compartment fire; notably, on the production of ghosting flames.

Generally, the occurrence of backdraft during a fire in confined surroundings is relatively related to several factors such as the mass fraction of unburned gases released by the fire, temperature of hot gases in the enclosure, dimensions of the room on the fire, characteristics of the burning fuel, and the velocity of the gravity current in the compartment. Focused on an experimental measurement campaign, the present paper aims to quantify the effect of confining on the behavior of fire in an interior medium compared to fire in an external or free medium.

\section{Experimental Domain}

The domain of the study consists of a reduced compartment of dimensions $1.20 \mathrm{~m} \times 1.20 \mathrm{~m} \times 1.02 \mathrm{~m}$ in which tests of fire in confined surroundings were carried out. A closed medium was obtained by closing all openings of the aforementioned domain after having ignited the fire source. The material of measurement consists of an automatic system for the acquisition of data called Agilent 34980A on which thermocouples of N-type were connected, whereby the heat source is ensured by the gas oil. The configuration of the thermocouples and the safeguard of data are by the use of a portable computer. Electric plate heating with a power of $1000 \mathrm{~W}$ allows the preheating of the fuel so that to bring up its initial temperature to an average of $60^{\circ} \mathrm{C}$. At the time of real fires, it can happen that certain internal or external factors modify the fire regimen; what influences directly its behavior in particular is the heat release rate of the source of the fire. In order to take this possible variation into account within the framework of this study, six hearths of cylindrical form with a height $h=50 \mathrm{~mm}$ and the different diameters $D$ were used as the source of fire in the experimental volume. Table 1 gives the diameter of each fire source used for the experimental campaign.

2.1. Devices of the Free and Confined Tests. Free fires are tests of fire performed in the free atmosphere, that is, without any boundary which can influence the development of fire. This latter is then naturally fed by the surrounding air. In order to be
TABle 1: Diameters of the sources of the fire tested in the experimental field.

\begin{tabular}{lcccccc}
\hline & $\begin{array}{c}\text { Source } \\
1\end{array}$ & $\begin{array}{c}\text { Source } \\
2\end{array}$ & $\begin{array}{c}\text { Source } \\
3\end{array}$ & $\begin{array}{c}\text { Source } \\
4\end{array}$ & $\begin{array}{c}\text { Source } \\
5\end{array}$ & $\begin{array}{c}\text { Source } \\
6\end{array}$ \\
\hline $\begin{array}{l}\mathrm{D} \\
(\mathrm{mm})\end{array}$ & 165 & 120 & 93 & 70 & 60 & 50 \\
\hline
\end{tabular}

able to perform such a fire, the tests were carried out in a sufficiently large room so that the outside wind cannot disturb the development of flames. By using turn by turn six fire sources, the test consists in igniting the source in the room and leaving it to freely burn in free air until the amount of fuel initially introduced in the hearth is exhausted. This action is timed to have the time spent by the fire before dying out. The temperature of the flame of each test is measured after every 5 seconds using the thermocouple THF plunged in the persistent zone of the flame (Figure 1). Confined fires are those evolving in a completely closed enclosure. There is no communication between the interior vitiated air and the external fresh air. Fire will be able only to use the oxygen contained in the interior air until there is a lack. The device consists in repeating the same scenario just like the tests in a free atmosphere, but in a completely closed volume. The probe thermocouple THF was slightly placed above the hearth to measure the temperature at the heart of the flame (Figure 2).

2.2. Procedure of Experiments. The launching of each test, regardless of the environment in which it is carried out, was done according to a well-defined procedure. The first stage consists in installing the experimental device and measuring the initial amount of fuel. This fuel is then preheated to reach an average temperature of $60^{\circ} \mathrm{C}$. Once the flame is set, temperature measurements are done automatically after every 5 seconds. Each test is thus repeated four times and only the average values are represented. The repeatability of the tests is checked by means of a statistical test [30].

2.3. Mass Loss Rate of Fuel. Fire is generally held according to three great phases, which are the growth phase, the fulldevelopment phase, and the decline phase. The most significant phase, besides the longest fire incidents, is the full-development phase. During this stage, fire reaches its steady state; that is, at this moment all sizes which are involved progress in a constant way. The mass loss rate which represents the average quantity of fuel which burns per unit time is determined from the surface area of the fire source $A_{f}$ and the speed of consumption of the fuel $w$ as shown by the following relation [31]:

$$
\dot{m}_{f}=\rho_{f} A_{f} w,
$$

with

$$
w=\frac{4 \Delta V}{\pi D^{2} t_{f}},
$$

where $D$ is the diameter of the fire source; $t_{f}$ is the duration of fire before dying out (time of the growth and full- 


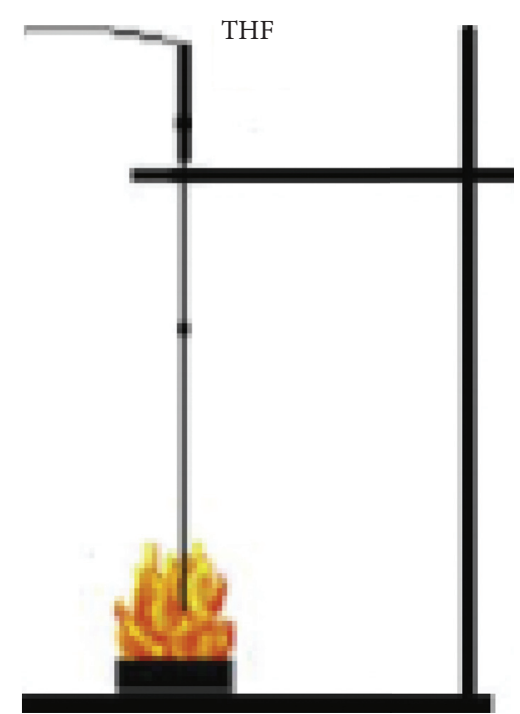

Figure 1: Device of free tests.

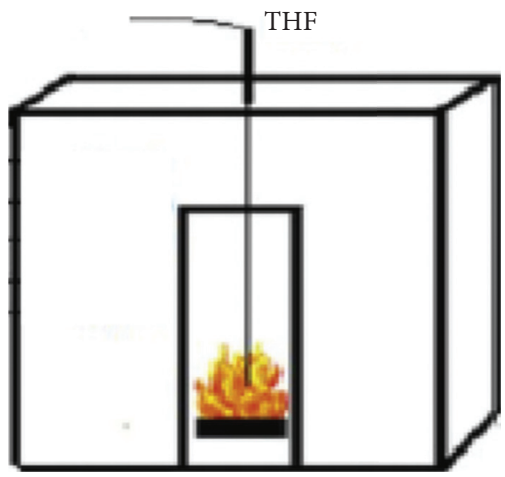

Figure 2: Device of confined tests.

development phases); and $\Delta V$ is the total mass really burnt during the fire. The heat release rate of the fire source is calculated owing to the following relation [32]:

$$
\mathrm{HRR}=\lambda_{c} \chi \dot{m}_{f} \Delta h_{\text {comb }} .
$$

The term $\lambda_{c}$ is the fraction of the convective heat delivered by the fire source. It is estimated at $0.70 ; \chi$ is the efficiency of combustion and is estimated at 0.82 for the diesel fuel; and $\Delta h_{\text {comb }}$ is the effective heat released by the combustion of $1 \mathrm{~kg}$ of fuel under conditions of an excess of oxygen without recovery of the heat contained in the released water vapor or diesel fuel. It is worth on average $42.2 \mathrm{MJ} / \mathrm{kg}[31]$.

\section{Experimental Results}

\subsection{Results of Fire Tests in Free Atmosphere}

3.1.1. Physical Description of Free Tests. Free tests were carried out with the aim of having a frame of reference behavior to compare it with that of the confined surroundings. Table 2 gives the initial volume $V_{i}$ of fuel introduced in each hearth like their average fire durations. It
TABLE 2: Results of the duration of fire according to each fire source used.

\begin{tabular}{lccc}
\hline Fire source no. & $D(\mathrm{~mm})$ & $V_{i}(\mathrm{ml})$ & $t_{f}(\mathrm{sec})$ \\
\hline Source 1 & 165 & 50.0 & 190 \\
Source 2 & 120 & 50.0 & 418 \\
Source 3 & 93 & 25.0 & 360 \\
Source 4 & 70 & 15.0 & 455 \\
Source 5 & 60 & 10.0 & 455 \\
Source 6 & 50 & 5.0 & 370 \\
\hline
\end{tabular}

can be noted that, for each used hearth and whatever the initial amount of fuel, the final volume is equal to zero. That is to say, the fuel was burnt in its totality. This is due to the fact that the fire is being held in a free atmosphere; thus there is permanent availability of fresh air, which makes it possible to continuously feed the fire source with oxygen contained in this ambient air. The combustion reaction will thus continue as long as there will still be fuel. The extinction of the flames will occur as soon as the fuel finishes.

Figures $3(a)-3(c)$ present the captured images of the flame during free tests with sources 1,3 , and 5 . It is noted according to the visual aspect that the larger the source is (particularly the diameter), the more the flame is unstable and thus turbulent. The larger the diameter of the hearth, the more the fuel is quickly exhausted that causes a fast extinction of flame. The more this diameter is large, the more the flame is of high level and thus emits high radiation.

As the study is purely experimental and each test is repeated four times, Figures 4 and 5 present the profiles of temperature in the persistent zone of the flame versus time for fire tests carried out with sources 1 and 6 . In these figures, the curves of the four repetitions along with their respective averages are illustrated. The calculation of the statistics of these curves made it possible to confront them with the table values (Table 3 ). That reveals that all calculated values are lower than the table values. It is, thus, a mathematical demonstration that variances of various repetitions are homogeneous. That means that fire tests are repeating with a degree of confidence of $95 \%$.

3.1.2. Main Characteristics of Free Tests. The main parameters which characterize fire on a macroscopic level are among other flame temperature $T_{F}$ and the mass loss rate of the fuel $\dot{m}_{f}$ which consequently has a direct impact on the duration $t_{f}$ and the heat release rate HRR of the fire. Table 4 presents the major results obtained following each fire source.

Figure 6 presents the variation of the duration of the fire and the mass loss rate of fuel according to the diameter of the fire source. On this figure, it is noted that, as the diameter of the fire source increases, the duration of fire decreases in an exponential way. This reduction is due to the fact that the medium flow of the fuel which burns increases with the diameter of the hearth and in particular the surface of the fire source. The chart of the thermal power generated by flames (Figure 7) shows a linear variation with the mass loss rate of 


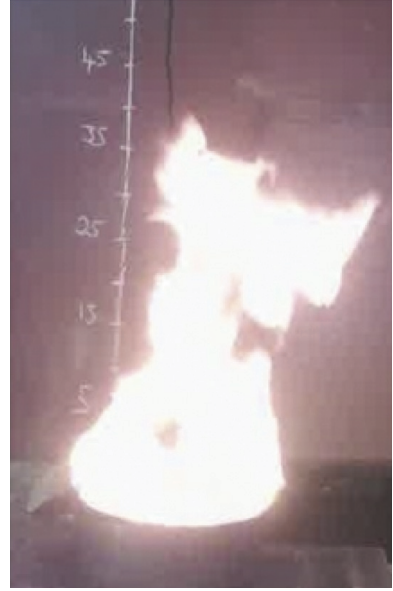

(a)

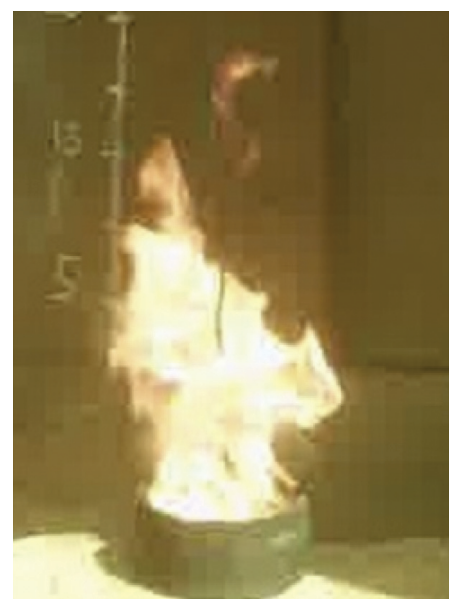

(b)

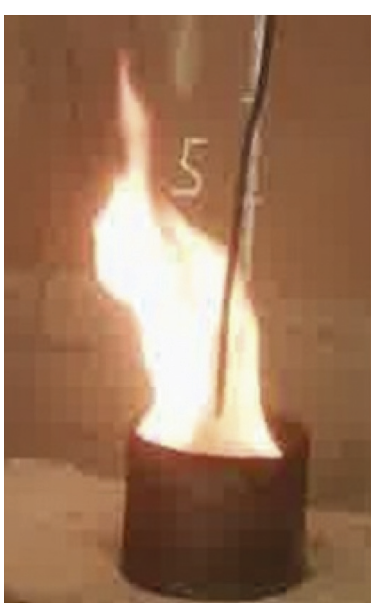

(c)

FIGURE 3: Images of flame during free fires: (a) source 1, (b) source 3, and (c) source 5.

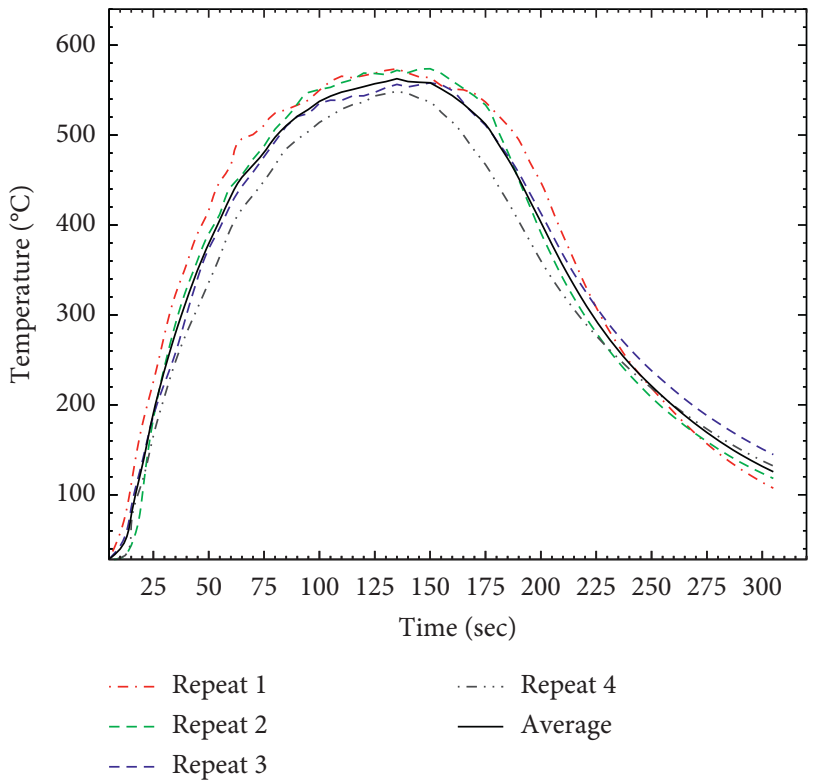

FIGURE 4: Flame temperature versus time: case study of free fire with fire source 1 .

fuel while the temperature of the flame remains constant around an average of $550^{\circ} \mathrm{C}$ and falls to value $450^{\circ} \mathrm{C}$ for the mass loss rate less than $0.03 \mathrm{~g} / \mathrm{s}$.

\subsection{Results of Fire Tests-Confined Room}

3.2.1. Physical Description of Confined Tests. Confined tests were done by using the same fire sources as previously. With the experimental domain being completely closed, the control of the evolution of fire was possible through the probe THF set above the fire source. Figures 8 and 9 thus represent the temporal profiles of the temperature of the flame of confined tests 1 and 6 . It is noted that the tests oscillate around an average curve which also presents three phases of the fire evolution known as growth, full-development, and decline.

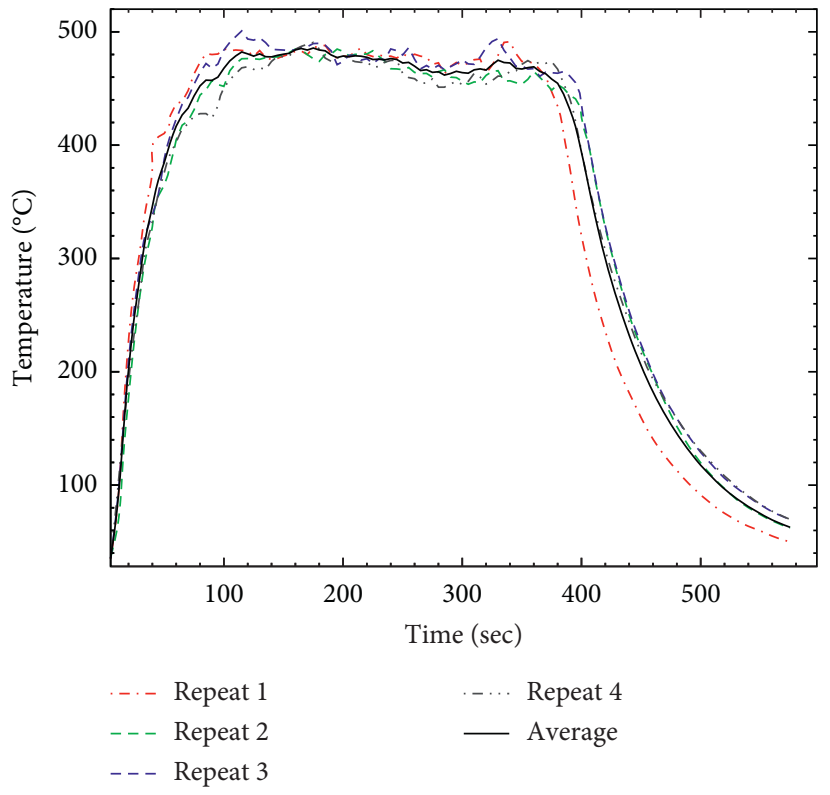

FIGURE 5: Flame temperature versus time: case study of free fire with fire source 6 .

TABLE 3: Application of Cochran's test on data of free fire tests.

\begin{tabular}{lcc}
\hline Fire source no. & $C_{\text {test }}$ & $C_{\text {table }}$ \\
\hline Source 1 & 0.280 & 0.341 \\
Source 2 & 0.259 & 0.312 \\
Source 3 & 0.280 & 0.315 \\
Source 4 & 0.293 & 0.310 \\
Source 5 & 0.287 & 0.310 \\
Source 6 & 0.289 & 0.312 \\
\hline
\end{tabular}

Contrary to fires in the open medium where the phase of extinction is generally due to the exhaustion of fuel, the extinction of fire in the confined medium is rather caused by the lack of the combustive element which is oxygen. Application of Cochran's test on the obtained data shows that there is also repeatability between confined tests with a 
TABle 4: Summary table of the results deduced from the free tests.

\begin{tabular}{lccccc}
\hline Fire source no. & $D(\mathrm{~mm})$ & $t_{f}(\mathrm{~min})$ & $\dot{m}_{f}(\mathrm{~g} / \mathrm{s})$ & $T_{F}\left({ }^{\circ} \mathrm{C}\right)$ & $\mathrm{HRR}(\mathrm{W})$ \\
\hline Source 1 & 165 & 3.17 & 0.215 & 560 & 570 \\
Source 2 & 120 & 6.97 & 0.098 & 560 & 2379.16 \\
Source 3 & 93 & 12.00 & 0.056 & 540 & 1368.02 \\
Source 4 & 70 & 25.27 & 0.027 & 450 & 654.27 \\
Source 5 & 60 & 37.92 & 0.018 & 471 \\
Source 6 & 50 & 61.67 & 0.011 & 436.18 \\
\hline
\end{tabular}

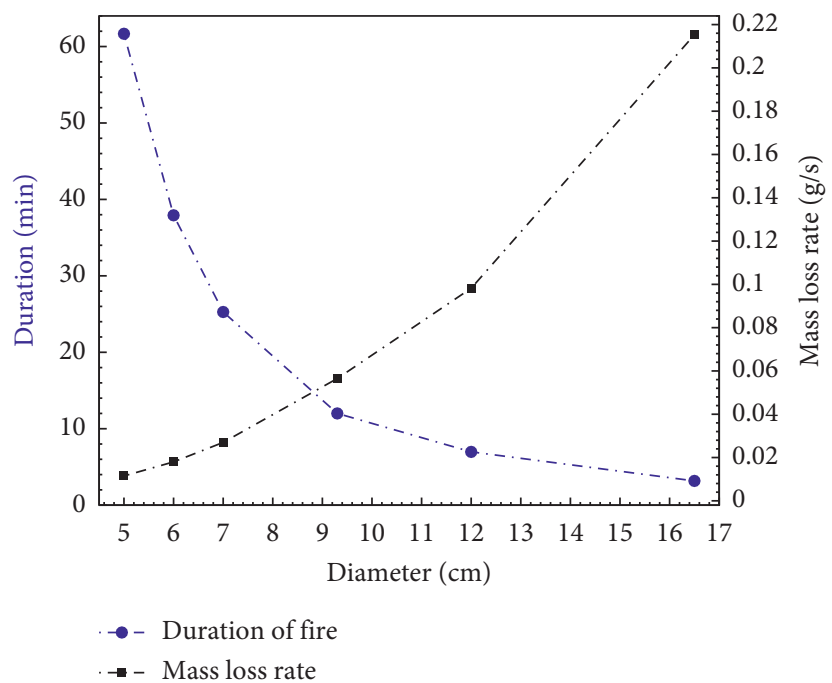

Figure 6: Variation of the fire duration and the fuel mass loss rate according to the fire source: case of fire in free atmosphere.

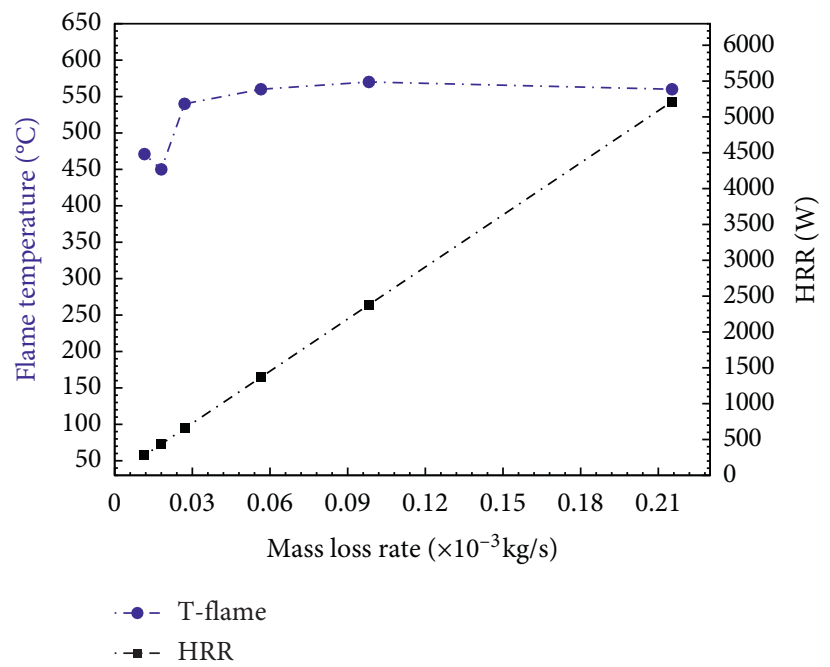

FIGURE 7: Variation of the flame temperature and the heat release rate according to the fire source: case of fire in free atmosphere.

degree of confidence of 95\%. As shown in Table 5, the calculated values of the various tests are all below the table values.

3.2.2. Main Characteristics of Confined Tests. Once the confined fire tests are performed, the calculation of the average values allowed obtaining Table 6 , which gives the same characteristics as in the case of tests in the external medium. The chart of the duration of the fire and the mass loss rate of fuel highlights profiles of similar variation with the tests in the opened environment (Figure 10). As illustrated in Figure 11, the variation of the heat release rate generated by the fire source remains also linear with the flow of fuel while the temperature remains constant with an average value of $450^{\circ} \mathrm{C}$. It increases with the average value of $550^{\circ} \mathrm{C}$ for the mass loss rate of fuel less than $0.03 \mathrm{~g} / \mathrm{s}$. 


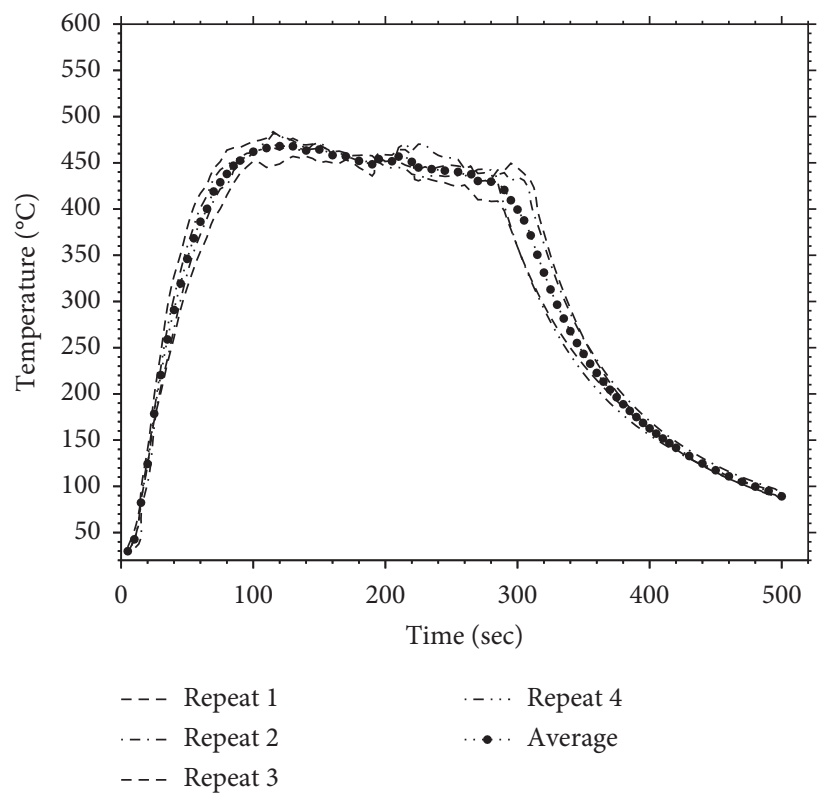

FIgURE 8: Evolution of temperature in the persistent zone of the flame during the four repeated tests: case of source 1.

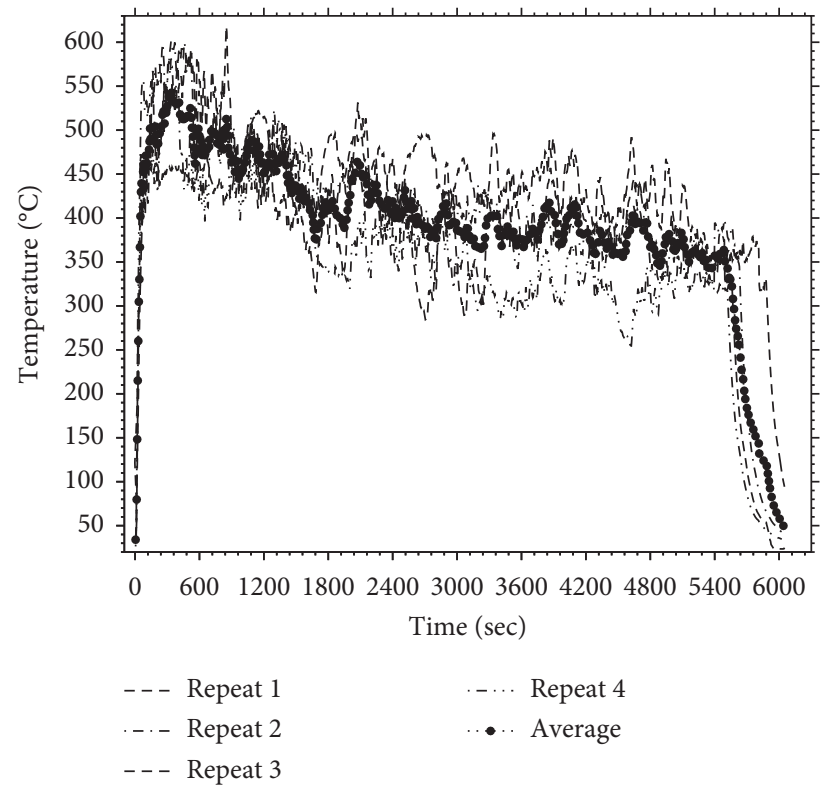

FIGURE 9: Evolution of temperature in the persistent zone of the flame during the four repeated tests: case of source 6.

TABle 5: Application of Cochran's test to data of the confined experiments.

\begin{tabular}{lcc}
\hline Fire source no. & $C_{\text {test }}$ & $C_{\text {table }}$ \\
\hline Source 1 & 0.270 & 0.312 \\
Source 2 & 0.295 & 0.321 \\
Source 3 & 0.277 & 0.318 \\
Source 4 & 0.279 & 0.332 \\
Source 5 & 0.294 & 0.322 \\
Source 6 & 0.333 & 0.356 \\
\hline
\end{tabular}

TABLE 6: Results obtained from tests of fire in confined surroundings.

\begin{tabular}{lccccc}
\hline Fire source no. & $D(\mathrm{~mm})$ & $t_{f}(\mathrm{~min})$ & $\dot{m}_{f}(\mathrm{~g} / \mathrm{s})$ & $T_{F}\left({ }^{\circ} \mathrm{C}\right)$ & $\mathrm{HRR}(\mathrm{W})$ \\
\hline Source 1 & 165 & 4.67 & 0.1759 & 470 & 3487.32 \\
Source 2 & 120 & 10.33 & 0.0778 & 440 & 1542.94 \\
Source 3 & 93 & 20.00 & 0.0377 & 470 & 747.62 \\
Source 4 & 70 & 42.67 & 0.0168 & 550 & 333.02 \\
Source 5 & 60 & 61.67 & 0.0105 & 550 & 207.64 \\
Source 6 & 50 & 92.00 & 0.0060 & 550 & 119.43 \\
\hline
\end{tabular}




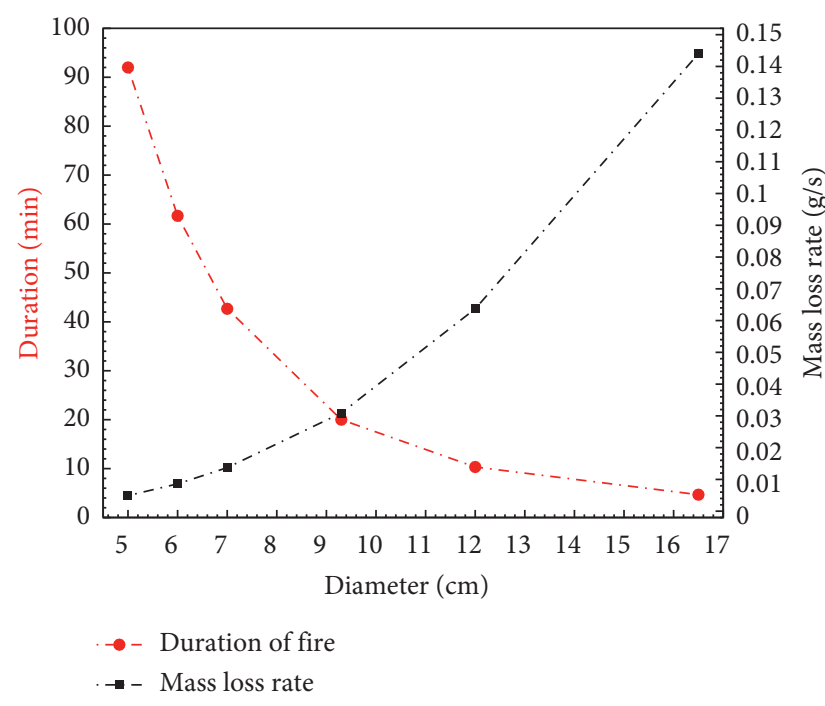

FIGURE 10: Variation of the fire duration and mass loss rate of fuel according to the source: case of confined tests.

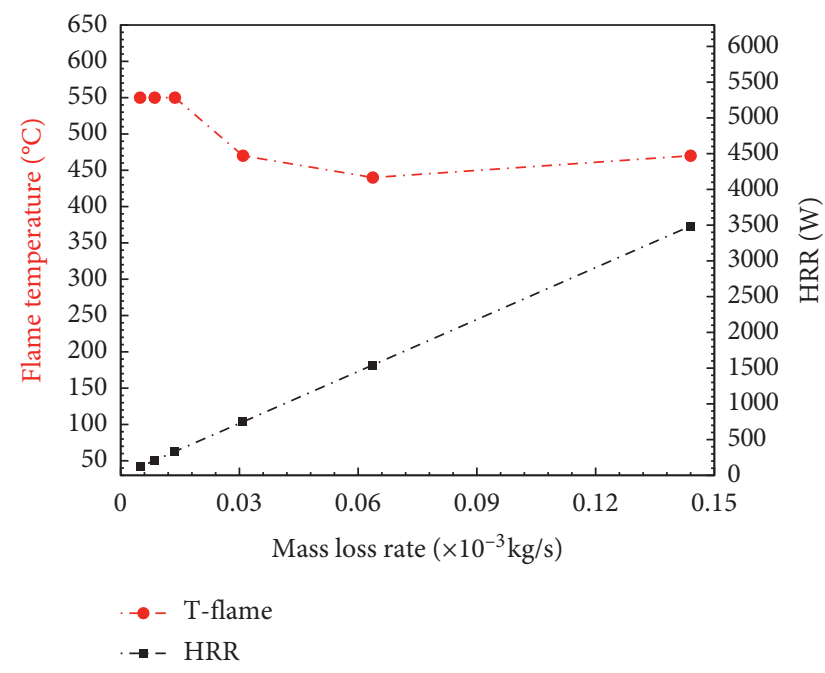

FIgURE 11: Variation of the flame temperature and heat release rate according to the mass loss rate: case of confined tests.

\section{Discussion of Results}

Confrontation of both tests makes it possible to put forward the level of influence of confining on an interior fire. Figures 12-14 highlight the effect of confining on the mass loss rate of fuel, the duration, and the heat release rate of fire. Although taking similar forms, one observes nevertheless a significant shift of the curve of the confined tests compared to the curve of free tests.

Plotting the confined test values in relation to the free test values allows quantifying the percentage of influence of

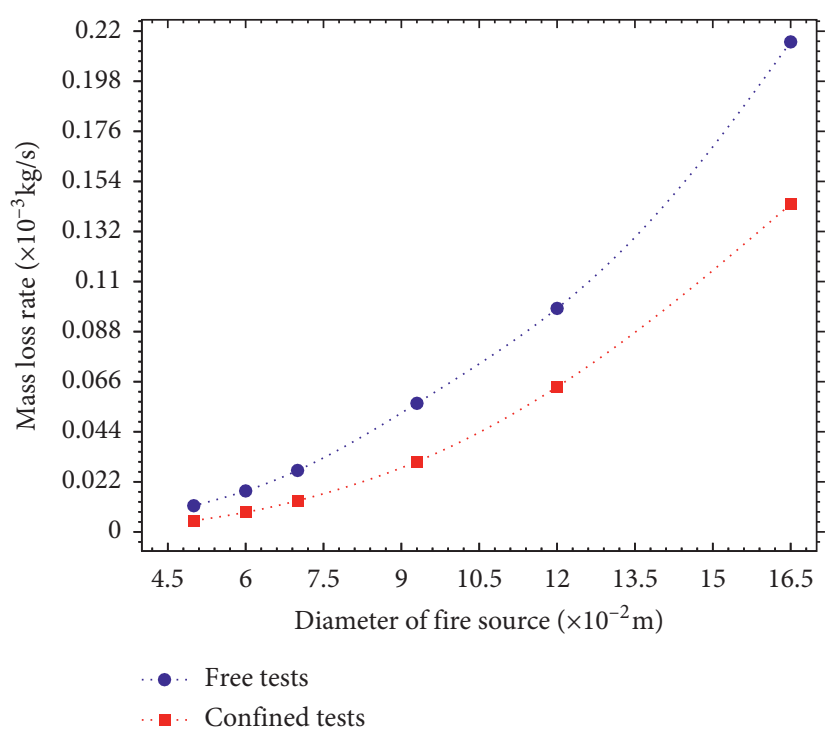

Figure 12: Variation of the mass loss rate of fuel in opened and confined surroundings.

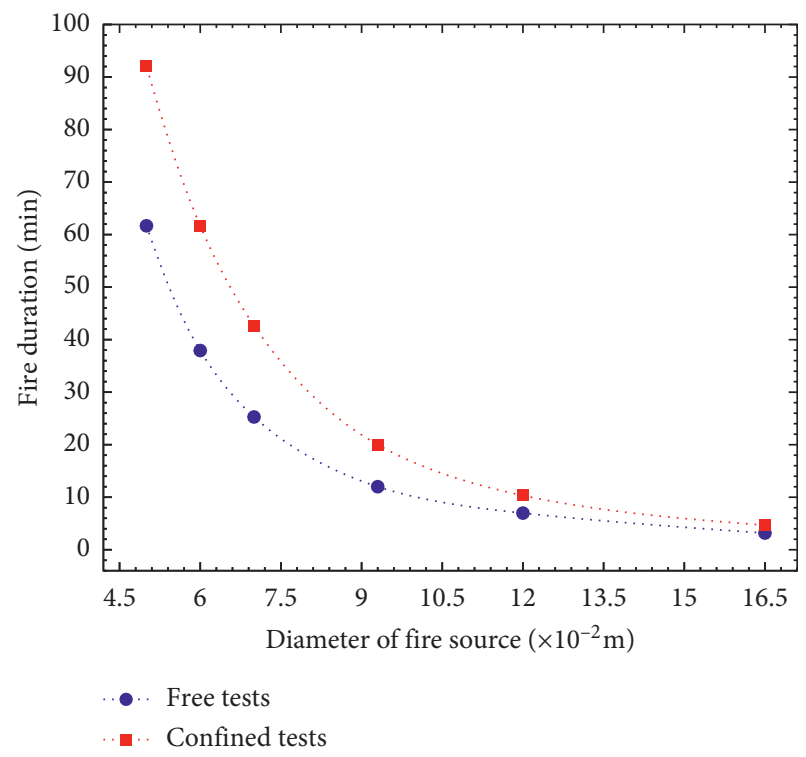

FIGURE 13: Variation of the duration of fire in opened and confined surroundings.

confining. Thus, a curve which passes through the first bisector assumes a percentage influence of the null effect. The extrapolation of the angle of the shift of one parameter compared to this data line quantifies the level of influence of confining on this parameter. A shift towards the right of the first bisector represents an increase in the effect, while a shift towards the left represents a reduction of the effect. Figures 15-17 represent the angles of shift of the mass loss 


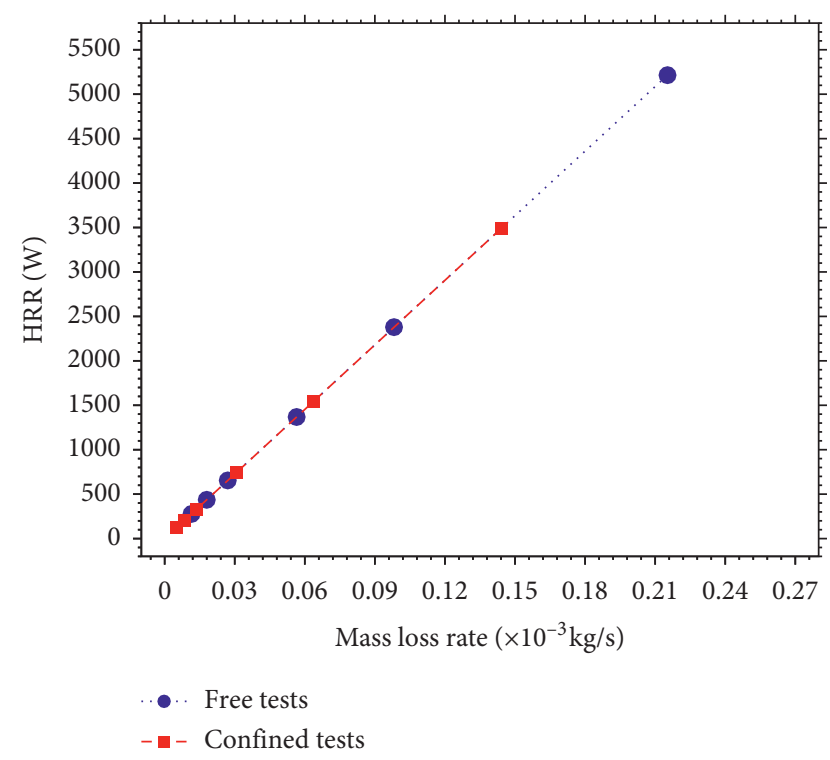

FIGURE 14: Variation of the heat release rate in open and confined surroundings.

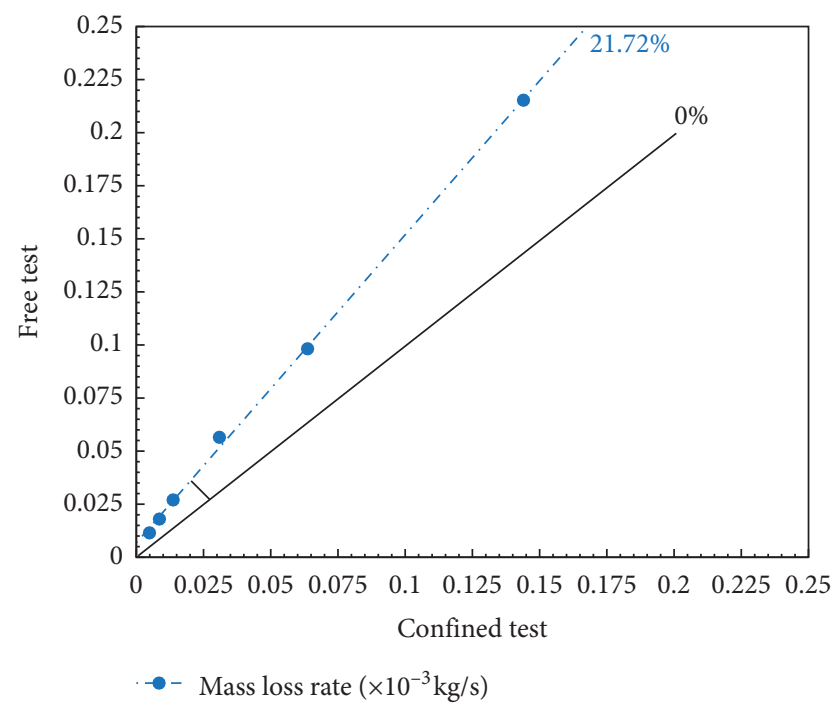

FIGURE 15: Angle of the shift of the effect of confining on the mass loss rate of fuel.

rate of fuel, the duration, and the heat release rate of fire. The determination of the values of these angles of shift made it possible to quantify the direction (increasing or reduction) and the influence level of confining on the fire tests carried out in the experimental room when it is completely closed (Table 7).

Thus, according to the results obtained within the framework of the present study, considering a fire evolving in an opened medium and developing a heat release rate HRR and spending a time $t_{f}$ to consume an amount of fuel $\Delta V$ with a mass loss rate $\dot{m}_{f}$; if the same fire is produced in confined surroundings, it would develop a thermal power $\mathrm{HRR}^{\prime}$ and would take a time $t_{f}^{\prime}$ to consume an amount of fuel $\Delta V^{\prime}$ with a mass loss rate of $\dot{m}_{f}^{\prime}$ (Table 8).

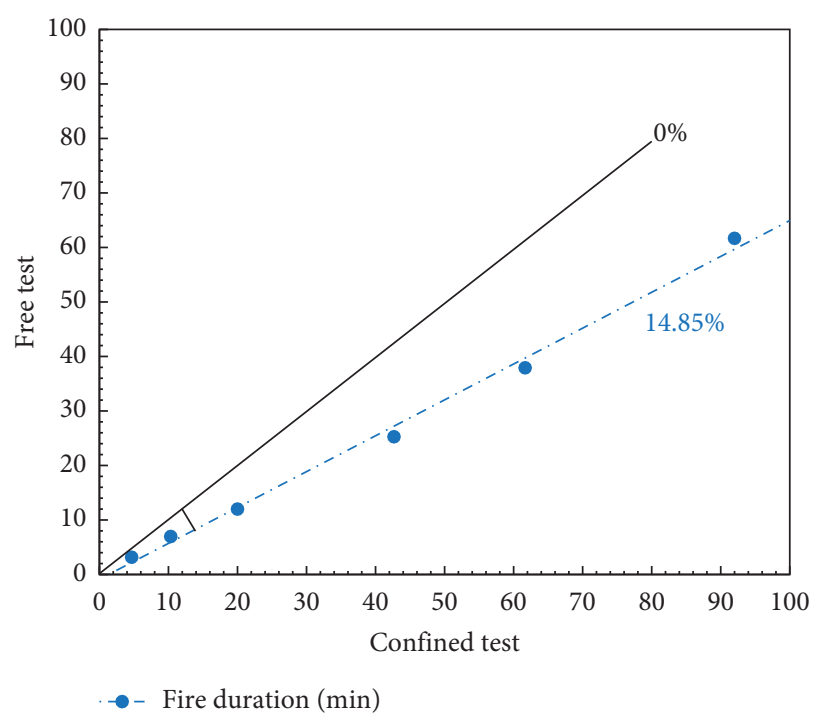

FIgURE 16: Angle of the shift of the effect of confining on the duration of fire.

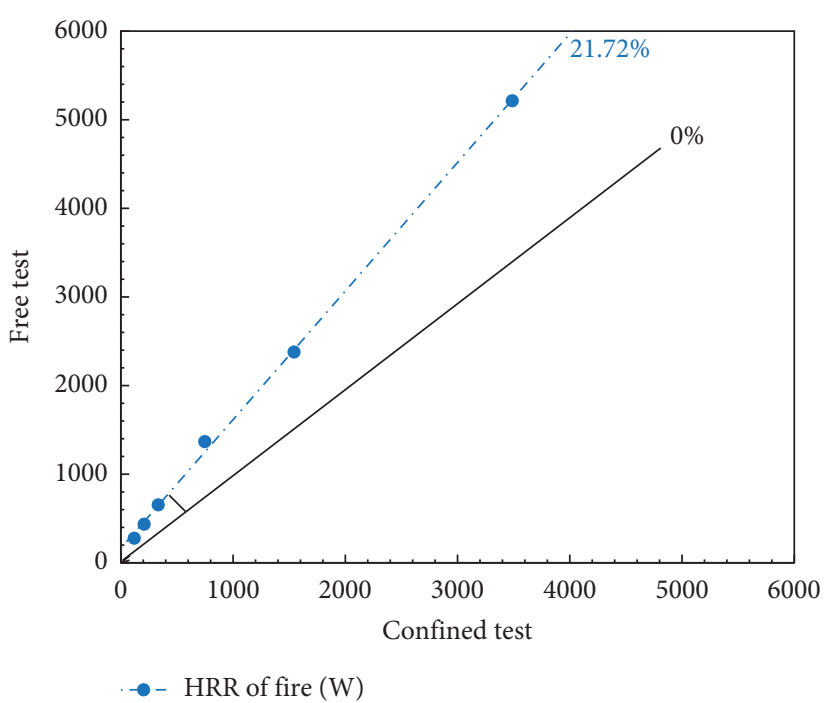

FIgUre 17: Angle of the shift of the effect of confining on the heat release rate of the fire source.

TABLE 7: Percentage and direction of influence of confining on the fire duration and heat release rate of the source.

\begin{tabular}{lc}
\hline Influenced parameter & Level of influence \\
\hline Fire duration $(\min )$ & $+14.85 \%$ \\
Heat release rate $(\mathrm{W})$ & $-21.72 \%$ \\
\hline
\end{tabular}

TABLE 8: Relations between parameters of fires in opened and confined surroundings.

\begin{tabular}{lc}
\hline Free test & Confined test \\
\hline $\mathrm{HRR}$ & $\mathrm{HRR}^{\prime} \cong 0.78 \mathrm{HRR}$ \\
$t_{f}$ & $t_{b}^{\prime} \cong 1.15 t_{f}$ \\
$\Delta V$ & $\Delta V^{\prime} \cong 0.5 \Delta V$ \\
$\dot{m}_{f}$ & $\dot{m}_{f}^{\prime} \cong 0.78 \dot{m}_{f}$ \\
\hline
\end{tabular}




\section{Conclusion}

The present paper has an objective, the study of the effect of confining on the behavior of a compartment fire. A trial run of fires of various heat release rates initially made in a free atmosphere has been performed in a confined domain. Analysis of measurements made after every five seconds enabled showing up comparatively in an open medium that the containment of fire reduces the average speed of consumption of fuel to 21.72 percent, which consequently decreases the heat release rate of the fire source. The duration of fire will be increased by $14.85 \%$. From these results in the confined room, it could be possible to predict the eventual moment a backdraft could occur during a confined fire.

\section{Abbreviations}

$\dot{m}_{f}$ : Mass loss rate of fuel in free tests $(\mathrm{g} / \mathrm{s})$

$\Delta V: \quad$ Initial amount of fuel in free tests (ml)

$t_{f}: \quad$ Duration of fire in free tests (min)

HRR: Heat release rate of free tests (W)

$\dot{m}_{f}^{\prime}$ : Mass loss rate of fuel in confined tests $(\mathrm{g} / \mathrm{s})$

$\Delta V^{\prime}$ : Initial amount of fuel in confined tests (ml)

$t_{b}^{\prime}$ : $\quad$ Duration of fire in confined tests ( $\mathrm{min}$ )

HRR': Heat release rate of confined tests (W)

$D: \quad$ Diameter of the fire source $(\mathrm{mm})$

$T_{F}: \quad$ Temperature of flame $\left({ }^{\circ} \mathrm{C}\right)$

$\rho_{f}: \quad$ Density of fuel (.)

$A_{f}: \quad$ Area of the fire source $\left(\mathrm{m}^{2}\right)$

$w: \quad$ Speed of the fuel steam $(\mathrm{m} / \mathrm{s})$

$\lambda_{c}: \quad$ Fraction of the convective heat (.)

$\Delta h_{\text {comb }}$ : Effective heat of combustion $(\mathrm{MJ} / \mathrm{kg})$

$\chi: \quad$ Efficiency of combustion (.).

\section{Data Availability}

No data were used to support this study.

\section{Conflicts of Interest}

The authors declare that they have no conflicts of interest.

\section{References}

[1] J. E. Bowen, "Flashover/backdraft explosive situation," Western Fire Journal, vol. 34, pp. 33-38, 1982.

[2] A. Coppalle, Feux de Compartiments, CNRS-Université de INSA de Rouen, Paris, France, 2010.

[3] P. H. Thomas, "Testing products and materials for their contribution to flashover in rooms," Fire and Materials, vol. 5, no. 3, pp. 103-111, 1981.

[4] T. L. Graham, G. M. Makhviladze, and J. P. Roberts, "On the theory of flashover development," Fire Safety Journal, vol. 25, no. 3, pp. 229-259, 1995.

[5] P. H. Thomas, M. L. Bullen, J. G. Quintiere, and B. J. McCaffrey, "Flashover and instabilities in fire behavior," Combustion and Flame, vol. 38, pp. 159-171, 1980.

[6] P. J. Pagni, "Diffusion flame analyses," Fire Safety Journal, vol. 3, no. 4, pp. 273-285, 1981.

[7] R. Borghi and M. Champion, Modélisation et Théorie des Flammes, Edition Technip, Paris, France, 2000.
[8] R. Borghi, La Combustion et les Flammes, Edition Technip, Paris, France, 1995.

[9] J. G. Quintiere, K. Steckler, and D. Corley, "An assessment of fire induced flows in compartments," Fire Science and Technology, vol. 4, no. 1, pp. 1-14, 1984.

[10] A. Hamins, E. Johnsson, M. Donnelly, and A. Maranghides, "Energy balance in a large compartment fire," Fire Safety Journal, vol. 43, no. 3, pp. 180-188, 2008.

[11] K. Kawagoe, "Fire behavior in rooms," Report no. 27, Building Research Institute, Tokyo, Japan, 1958.

[12] V. Babrauskas, "Estimating room flashover potential," Fire Technology, vol. 16, no. 2, pp. 94-103, 1980.

[13] B. J. McCaffrey, J. G. Quintiere, and M. F. Harkleroad, "Estimating room temperatures and the likelihood of flashover using fire test data correlations," Fire Technology, vol. 17, no. 2, pp. 98-119, 1981.

[14] W. K. Chow, "New inspection criteria for flashover in compartmental fires," Fire and Materials, vol. 23, no. 1, pp. 13-15, 1999.

[15] L. Sungchan and H. Kazunori, "A simplified formula for occurrence of flashover and corresponding heat release rate," Procedia Engineering, vol. 62, pp. 292-300, 2013.

[16] W. K. Chow and J. Liu, "Application of nonlinear dynamics in studying flashover fire in a small open kitchen," Journal of Applied Mathematics and Physics, vol. 4, no. 5, pp. 914-924, 2016.

[17] M. Fleischann and Z. Chen, "Defining the difference between backdraft and smoke explosions," Procedia Engineering, vol. 62, pp. 324-330, 2013.

[18] D. T. Gottuk, R. J. Roby, M. J. Peatross, and C. L. Beyler, "Carbon monoxide production in compartment fires," Journal of Fire Protection Engineering, vol. 4, no. 4, pp. 133150, 1992

[19] D. T. Gottuk, R. J. Roby, and C. L. Beyler, "The role of temperature on carbon monoxide production in compartment fires," Fire Safety Journal, vol. 24, no. 4, pp. 315-331, 1995.

[20] R. Mouangue, M. P. Onguene, T. J. Zaida, and F. H. Ekobena, "Numerical investigation of critical velocity in reduced scale tunnel fire with constant heat release rate," Journal of Combustion, vol. 2017, Article ID 7125237, 12 pages, 2017.

[21] G. Kagou, B. Kola, and R. Mouangue, "CFD studies of the propagation and extinction of flame in an under-ventilated and over-ventilated enclosure," Journal of Taibah University for Science, vol. 10, no. 3, pp. 393-402, 2016.

[22] A. Mbainguebem, R. Mouangue, and B. T. Bianzeube, "CFD studies of soot production in a coflow laminar diffusion flame under conditions of micro-gravity in fire safety," Journal of Taibah University for Science, vol. 11, no. 4, pp. 566-575, 2017.

[23] C. M. Fleischmann, P. J. Pagni, and R. B. Williamson, Exploratory Backdraft Experiments, University of California, Berkeley, CA, USA, 1993.

[24] D. T. Gottuk, M. J. Peatross, J. P. Farley, and F. W. Williams, "The development and mitigation of backdraft: a real-scale shipboard study," Fire Safety Journal, vol. 33, no. 4, pp. 261-282, 1999.

[25] W. G. Weng and W. C. Fan, "Critical condition of backdraft in compartment fires: a reduced-scale experimental study," Journal of Loss Prevention in the Process Industries, vol. 16, no. 1, pp. 19-26, 2003.

[26] G. Guigay, D. Gojkovic, L.-G. Bengtsson, B. Elíasson, and B. Karlsson, "The use of CFD calculations to evaluate firefighting tactics in a possible backdraft situation," Fire Technology, vol. 45, no. 3, pp. 287-311, 2009. 
[27] J. C. Perez, G. Guigay, B. Karlsson et al., "Influence of obstacles on the development of gravity current prior to backdraft," Fire Technology, vol. 45, pp. 323-340, 2009.

[28] J. Wu, Y. Zhang, X. Gou, M. Yan, E. Wang, and L. Liu, "Experimental research on gas fire backdraft phenomenon," Procedia Environmental Sciences, vol. 11, pp. 1542-1549, 2011.

[29] F. M. Vondou, C. V. N. Abbe, J. T. Zaida, P. O. Mvogo, and R. Mouangue, "Experimental study on fire behaviour in room following the disposition of openings," Journal of Combustion, vol. 2020, p. 11, Article ID 9385712, 2020.

[30] B. Y. Lemeshko and E. P. Mirkin, "Bartlett and Cochran tests in measurements with probability laws different from normal," Measurement Techniques, vol. 47, no. 10, pp. 960-968, 2004.

[31] P. O. Mvogo, R. Mouangue, J. T. Zaida, M. Obounou, and H. E. Fouda, "Building fire: experimental and numerical studies on behaviour of flows at opening," Journal of Combustion, vol. 2020, p. 11, Article ID 2535073, 2020.

[32] S. P. Nowlen, Heat and Mass Release for Some Transient Fuel Sources Fires: A Test Report, U.S. Nuclear Regulatory Commission, Washington, DC, USA, 1986. 